\title{
PEDRO RÚJULA y MANUEL CHUST, EI Trienio Liberal. Revolución e independencia (1820-1823), Los libros de la Catarata, Madrid, 2020.
}

Posiblemente 2020 será recordado por las generaciones actuales, en el futuro más inmediato, y cabe pensar que por las venideras durante, al menos, algunos decenios, como el año del Coronavirus (Covid-19). Y aunque todavía sea pronto, en el momento en que se escriben estas páginas, para hablar de sus ulteriores repercusiones, cabe pensar, razonablemente, que marcará un antes y un después en la historia actual. Pero historiográficamente hablando, al menos para los historiadores dedicados a la contemporaneidad en general y al siglo XIX en particular, es el año en que se conmemora el bicentenario del Trienio Liberal. Pues el periodo histórico que comienza con la Revolución de 1820 fue un punto de inflexión en la historia, "un seísmo político" como acertadamente lo nombran los autores de este libro. Cuyo epicentro fue España, pero cuyas ondas se sintieron en el Mediterráneo y en el Atlántico. Razón por la que cabe hablar de una oleada revolucionaria que sacudió buena parte del mundo.

Al lector versado no se le escapa que hablar del Trienio es hacerlo de la segunda etapa de la Revolución española del siglo XIX, que por sus enormes repercusiones tiene un nombre propio y por ende jalona la historia española decimonónica. Y precisamente este es el primer objeto del libro: explicar por qué "1820 no era ni 1808 ni 1810" y "releer" la política del segundo periodo constitucional de la historia española, donde, por cierto, la Constitución de 1812 alcanzó mayor desarrollo práctico de las tres ocasiones donde estuvo vigente, "sobre nuevas bases". Es decir, aportar una mirada más cercana a los propios hechos y más alejada de las interpretaciones ideológicas que distintos grupos políticos hicieron posteriormente al respecto, y que en general, interpretaban el Trienio como un fracaso, caso del conservadurismo, o como una revolución traicionada e inconclusa, caso de los progresistas. Tratando de sumergirse, y de su mano al lector, en las propias posibilidades teóricas y prácticas que tuvo el proceso revolucionario en acto más que en potencia.

La otra gran meta de este libro es prestar la debida atención tanto a los hechos internos como externos que condicionaron el Trienio y fueron condicionados por el triunfo de la Revolución de 1820. No mediante la minusvaloración de la propia coyuntura española peninsular, al revés, pues queda muy bien 
resuelta como cabe esperar de un producto de este tipo hecho por buenos profesionales, sino porque se ha sabido conjugar en todo momento con lo acaecido en Hispanoamérica y en Filipinas. En las distintas naciones soberanas de hoy que, sin embargo, todavía no existían en 1820 y formaban parte de las posesiones de la monarquía hispana. Y tratándolas de esa manera histórica se trata de evitar caer en una visión presentista o nacionalista sobre el pasado. A la postre, sin duda alguna, para el público español esta es una de las principales novedades. Pero aún a riesgo de equivocarnos, posiblemente también para el público latinoamericano. En el fondo son más los estudios que analizan la importancia que tiene la crisis colonial para la quiebra del Antiguo Régimen español, que los que hacen lo propio con la importancia que tuvo el constitucionalismo español para el proyecto independentista americano. Por un lado porque el interés sobre el desarrollo del Trienio en América y Filipinas es bastante reciente entre la historiografía española, y por otro lado, porque la reacción del realismo americano no había sido tratada en su justa media por parte de la historiografía de los distintos países que surgieron tras declarar la independencia de España durante el Trienio.

Estos dos propósitos fundamentales se materializan, sobresalientemente, tanto en la forma como en el fondo. Lo primero porque la obra se divide en dos partes que ocupan prácticamente la mitad de la obra cada una. De forma que sin contar con la introducción, el apartado cronológico y la parte final dedicada a reflejar la bibliografía utilizada para escribir este libro, hay cinco capítulos dedicados a la explicación de los hechos peninsulares, sin perder de vista el impacto europeo que tuvo el Trienio, y otros tantos que hacen lo propio con la situación de las colonias ultramarinas. Lo segundo, porque no se nos escapa que los autores, los profesores Rújula y Chust, son especialistas en el periodo, y ambos han sabido elegir cuidadosamente la perspectiva en la que se ha configurado la obra. El primero como autor de textos de referencia para el estudio del Trienio en España; el segundo como buen conocedor de la influencia que el liberalismo doceañista tuvo en América. Pero también porque se apoyan tanto en estudios fundamentales sobre el periodo histórico como en la documentación generada durante el mismo. Lo cual permite combinar a cada paso la mirada del historiador con las miradas de los actores históricos, pero sin dejar que la narración malogre la interpretación de los hechos ni, al revés, que la interpretación silencie totalmente las voces del pasado.

Otra característica de la obra es su brevedad. Se trata de un trabajo que tiene 190 páginas, pero a las que si les restamos las pocas páginas protocolarias, indiciarias y bibliográficas, que todo ensayo tiene, es capaz de explicar las claves del Trienio en poco más de 180 páginas. Lo que es tanto un reto intelectual (no siempre escribir más equivale a explicar mejor) como una exigencia editorial, tal y como explicaron los autores de la obra en la presentación que se hizo de ella en Sevilla el marzo pasado, en el contexto del congreso "La llusión de la libertad. El liberalismo revolucionario en España y América en los años 20". Y 
además destaca que se haya concebido a modo de "síntesis interpretativa" de la época, es decir, que ofrece al mismo tiempo una visión panorámica pero simultánea: somos capaces de seguir el pulso del Trienio dentro de sus tiempos en todos los rincones del mundo donde se proclamó la Constitución de 1812, independientemente de que se trate de la España peninsular o de la España colonial. Lo cual ha obligado a los autores a ser muy precisos en los distintos análisis que ofrece, ser parcos a la hora de seleccionar las lecturas y citar al pie de página, pero no por ello ofrecer una lectura reduccionista de las diferentes tramas políticas que el Trienio trajo consigo.

Dentro del análisis, fundamentalmente político porque eminentemente política fue la Revolución de 1820, la variedad temática obliga al lector a hacerse cargo de la riqueza, interés y complejidad del periodo: la importancia de los militares para verificar el cambio político, el papel desempeñado por la Corona y la Iglesia como legitimadores sociales de la política, la articulación de la política liberal en las Cortes y en la calle, la formación de distintos partidos políticos liberales, la proliferación de la prensa política, las distintas conspiraciones contrarrevolucionarias y la complejidad del movimiento realista, el rol que desempeñó la diplomacia, la injerencia de las potencias extranjeras, la influencia del constitucionalismo doceañista fuera de los territorios hispanos... Son varios de los puntos fundamentales que se abordan a lo largo de las páginas que componen este libro. A ello se dedican los capítulos que van del primero al tercero y del noveno y el décimo. Estos son los que principalmente se dedican al análisis de la historia de la España peninsular. Pero esas mismas categorías sumadas a otras más específicas como la cuestión indígena, que es una de las más destacadas como contrapunto, sirven para entender lo que sucedía al mismo tiempo en las colonias españolas.

Por otro lado, del análisis de la situación americana y filipina, destaca una división territorial que ayuda a comprender mejor la complejidad de los sucesos vividos en los distintos territorios que componían la monarquía hispana allende los mares. Pues en demasiadas ocasiones los historiadores españoles tendemos, inconscientemente y por costumbre, a hablar de Hispanoamérica como si se tratase de un todo único, como nos amonestan, amigablemente y con razón, nuestros colegas americanos. Cuando lo cierto es que los destinos de todas las colonias no fueron unidireccionales ni estaban determinadas a independizarse. Razón por la que cada territorio tuvo su propio ritmo aunque tocasen al mismo compas, liberal, de los tiempos. Si bien en conjunto se puso igualmente en vigor la Constitución de 1812 y muchos de los acontecimientos vividos en España tienen su correlato hispanoamericano, los desarrollos de cada territorio tuvieron sus propias lógicas.

Por ejemplo, el capítulo octavo se dedica a las islas de Cuba y Filipinas, que como sabemos permanecieron dentro del orden español, ya fuera constitucional o absoluto, hasta finales del siglo XIX, y que salvo alguna excepción no fueron espacio de luchas violentas durante el periodo constitucional del Trienio 
al que se sujetaron sin mucha variación de la estructura interna colonial. Y que presentan, en conjunto, algunas diferencias entre sí y frente a la América continental, donde posteriormente sí se produjeron los procesos de independencia que dieron paso a la creación de nuevas naciones liberales. Pero también frente a otros territorios insulares que como Santo Domingo declaró su independencia. Al mismo tiempo y debido a las distintas correlaciones de fuerzas entre realistas y liberales dadas en las poblaciones de la América continental, y a los distintos proyectos conservadores, reformistas o insurgentes que surgieron en varios territorios, ya fueran éstos más o menos absolutistas, autonomistas o totalmente independentistas, partidarios de la monarquía española, una monarquía propia o el establecimiento de repúblicas, no cabe hacer un análisis de la América continental monolítico ni único. Razón por la que el capítulo quinto se enfoca en el territorio de Nueva España que al final dio lugar al Imperio mexicano. El sexto se ocupa de Centroamérica, que pasó de estar en la órbita del México independiente para luego crear una suerte de federación de las Provincias Unidas del Centro de América, como solución conjunta de los intereses guatemaltecos, salvadoreños, hondureños y costarricenses.

El séptimo capítulo hace lo propio con Sudamérica, en donde la tesitura fue mucho más bélica que en los territorios anteriores. En parte como herencia de los últimos momentos absolutistas previos al inicio del Trienio Liberal, ya que la República de Colombia -uno de los primeros éxitos del movimiento bolivariano- ya se había establecido desde 1819, y San Martín había liderado las independencias de Chile y Argentina anteriormente a 1820. Pero donde también se dejaron sentir los envites que el constitucionalismo peninsular trajeron consigo, y su consiguiente enfrentamiento con las fuerzas realistas coloniales y con el propio proyecto bolivariano, que en algunos puntos era menos liberal que el proyecto doceañista pero al que se veía como algo propio por parte de buena parte de la burguesía criolla. Todo lo cual terminó con la independencia y anexión de territorios que hoy día componen Ecuador, Venezuela y Panamá para la Gran Colombia liderada por Bolívar, y la posterior toma de Perú por parte de San Martín, si bien el antiguo virreinato del Perú no logró ser totalmente independiente hasta 1824 puesto que el territorio peruano quedó dividido entre una zona de influencia insurreccional y otra realista. Toda vez Fernando VII volvió a reponer el absolutismo en España gracias a la ayuda del Ejército francés, los famosos Cien Mil Hijos de San Luís, que en 1823 terminó con la segunda experiencia constitucional española y dio alas a la línea más dura de la contrarrevolución española que había tratado de minar, sin éxito pero sin tregua, a los gobiernos liberales del Trienio. Y que persiguió hasta la muerte, castigando con el presidio, la ejecución o el exilio, a todos los personajes que se habían significado por el orden constitucional.

En resumen, se trata de una obra muy bien compuesta y que cumple con las expectativas que los autores crean en la introducción del libro. En ese sentido resulta tremendamente coherente entre los objetivos que se persiguen y el modo 
de alcanzarlos. Lo cual, unido a su ágil lectura, en gran medida favorecida por su vocación sintética y la poca extensión de los epígrafes de los que se componen cada capítulo, y a la narración tan precisa como rigurosa que se hace de las diferentes perspectivas que se abordan, resulta en que sea un trabajo altamente recomendable tanto para investigadores, docentes y estudiantes como para el público neófito que está interesado en el periodo. Ya que no es una etapa histórica muy conocida para toda la importancia que el periodo tuvo para la historia de España e Hispanoamérica de ese momento y posteriormente, y todavía hoy muchos piensan que el Himno de Riego o El Trágala son sendas creaciones originales de la Segunda República Española.

El público especializado encontrará un apoyo para contextualizar sus propios trabajos y sus propias lecciones sobre el Trienio en la misma medida en que se han actualizado algunas interpretaciones historiográficas del pasado, debido a la incorporación de nuevos trabajos aparecidos en las últimas décadas, así como un excelente marco conceptual e interpretativo para señalar los principales rasgos del periodo histórico. Quien no lo sea, tiene la oportunidad de comprender con sencillez la importancia que estos tres años de constitucionalismo tuvieron en sí mismos y dentro del primer liberalismo español en el siglo XIX, así como de contagiarse de la inmediatez y viveza del proceso revolucionario, donde nada estaba escrito, salvo la Constitución de 1812, y todo estaba por hacer para superar el Antiguo Régimen.

Si no se logró hacer entonces, no fue tanto por la división de los liberales entre moderados y exaltados, la participación popular en la política y en la milicia, la fuerza de la Corona y de la Iglesia o la sempiterna presencia de los elementos internos reaccionarios, sino por la confabulación de estos últimos con la Francia absolutista, el temor de las potencias europeas a que el ejemplo español cundiera en todo el continente, como ya hizo en Portugal e Italia, y la invasión de un Ejército extranjero venido desde Francia y ayudado por la contrarrevolución española.

Sergio Cañas Díez

Instituto de Estudios Riojanos sergio.canas@unirioja.es 